\title{
COVID changes to Post Anaesthesia Care Unit nursing practices
}

Follow this and additional works at: https://www.journal.acorn.org.au/jpn

Part of the Perioperative, Operating Room and Surgical Nursing Commons (c) (i)

This work is licensed under a Creative Commons Attribution 4.0 License.

\section{Recommended Citation}

Stapleton, Heather J. Ms (2021) "COVID changes to Post Anaesthesia Care Unit nursing practices," Journal of Perioperative Nursing: Vol. 34 : Iss. 2 , Article 3.

Available at: https://doi.org/10.26550/2209-1092.1113

https://www.journal.acorn.org.au/jpn/vol34/iss2/3

This Project report is brought to you for free and open access by Journal of Perioperative Nursing. It has been accepted for inclusion in Journal of Perioperative Nursing by an authorized editor of Journal of Perioperative Nursing. 


\section{Author}

Heather J Stapleton

MNursingEd, PGradDipAcuteTraumaNsg, PGradDipPeriopNsg, BSc (Nursing)

\title{
COVID-19 changes to Post Anaesthesia Care Unit nursing practices
}

\begin{abstract}
The pandemic year of 2020 brought unparalleled and swift changes to health care processes within Australia. All registered nurses in the Post Anaesthesia Care Unit (PACU) of a regional tertiary referral hospital had to make changes to routine personal protective equipment (PPE) practice to accommodate a safer environment for both staff and patients. Changes to PPE practices included the addition of heat moisture exchange (HME) filters to laryngeal mask airways (LMAs), and the use of Level 3 surgical masks during aerosolising procedures such as extubation and nebulisation. Changes were also made to the structured handover from anaesthetic nurse to the PACU to increase compliance with PPE practice.
\end{abstract}

\section{Identified problem}

COVID-19 is an infectious airway disease, spread primarily through droplets of saliva or discharge from the nose'. The COVID-19 pandemic required extensive policies and procedures to be created and implemented within the perioperative unit for patients who were suspected or confirmed COVID-19 cases. However, data suggests asymptomatic or mild infections account for 80 per cent of cases, and asymptomatic patients are likely to journey through the operating theatre without implementation of the personal protective equipment (PPE) precautions recommended for airborne particles².

The perioperative environment was identified as a high-risk environment for aerosolising procedures ${ }^{1}$. Routine practice within the perioperative unit includes manual ventilation, intubation, extubation, suctioning and nebulisation which all produce small particles of fluid from the patient's airways that can flow through the air, spread widely and settle on surfaces in the environment?
The Post Anaesthesia Care Unit (PACU) in this report has 18 bed spaces and, on average, it accommodates 290 elective and emergency surgical patients a week. The 18 bed spaces are divided into three bays of six beds; when at capacity in stage one PACU, there is a minimum of 12 people, both staff and patients, within each bay. It was therefore identified that this workspace, with less than 1.5 metres between each bed space, does not allow staff and patients to maintain the physical distancing of at least 1.5 metres that is advised to reduce the spread of COVID-193. Additionally, when compared to operating theatres, the PACU has no high efficiency particulate air (HEPA) filter, which would remove small (0.1-1 micron) airborne particles 4 .

PPE is used to safeguard health care workers and patients. Prior to the pandemic, routine PPE worn by staff in the PACU during care of non-infectious patients from admission to discharge included surgical scrubs, fabric or disposable surgical hats, gloves and safety goggles ${ }^{5}$. Traditionally, the heat moisture exchange (HME) anaesthetic filters used intra-operatively were 
removed from the laryngeal mask airways (LMAs) on transfer from the operating theatre (OT), and patients were received in the PACU with no HME filter on the airway. Coughing during extubation from an LMA within the PACU is common and without the HME filter in place or a HEPA filter within the unit fluid particles from the patient's airway can be expelled directly into the PACU environment, spreading to both staff and other patients and remaining in the environment ${ }^{2}$. It was identified that COVID-19 particles are smaller than five micron and the HME filters are verified to particles smaller than two micron ${ }^{6}$. Additionally, COVID-19 particles can stay in the air for several hours and fomites can remain active on plastic surfaces within the environment for 72 hours ${ }^{1,5,6}$. Due to this, changes to routine PPE practices within the PACU had to be made to safeguard both staff and patients during the COVID-19 pandemic.

\section{Proposed solution}

PPE for airborne precautions and strict adherence to infection control policy and procedure were in place for patients who were suspected or confirmed to have COVID-19; however, measures for asymptotic COVID-19 patients needed to be implemented. To protect both patients and staff from asymptotic COVID-19 carriers, changes to routine PPE use within the PACU were introduced. HME filters were left on patient's LMA during transfer from the OT to the PACU and Level 3 masks became routine PPE for staff caring for a patient with an airway in place or when performing aerosolising procedures. Level 3 surgical masks are used for droplet and contact precautions, and in relation to COVID-19 they are used when in contact with or during direct care of a person who is confirmed or suspected of having COVID-196,7, The anaesthetic team also worked toward decreasing the use of re-usable LMA's within the OT and, when appropriate, using single-use airways to reduce the risk of cross-contamination from faulty sterilisation. Additionally, the structure of the ISBAR (Identification, Situation, Background, Assessment and Request or Recommendation) nursing handover between anaesthetics and PACU was refined to improve PPE change compliance.

\section{Implementation strategies and opportunities for improvement}

This project was a collaboration between medical and nursing staff within the perioperative unit. Communication regarding implementation of this project occurred during staff meetings and in emails between PACU and anaesthetic team leaders. A change of practice was instigated by the anaesthetic department (medical and nursing), to ensure HME filters were left on patient LMAs during transport from the OT to the PACU. Additionally, single-use LMA stock levels were increased by the stores department, and the use of re-usable LMAs by anaesthetic staff was discouraged. However, nation-wide stock shortages at the beginning of COVID-19 did not facilitate this change to single-use airways.

Most staff members, both medical and nursing, embraced the changes in routine PPE practice without issue; however, a small subset of staff showed a consistent aversion to implementing the changes. After a general staff meeting where the reason for the changes to PPE practice were discussed, compliance did improve. Additionally, since the project was carried out in a university teaching hospital, the regular changeover of medical staff meant that HME filters could be routinely left off LMAs when patients were transferred to the PACU. If compliance was seen to be decreasing a general email was sent to both medical and nursing anaesthetic staff to ensure they are aware of practice changes and the importance of compliance to safeguard both patients and colleagues.

\section{Project successes}

Prior to the patient arriving in the PACU, the PACU team leader receives verbal phone handover about the patient from an anaesthetic nurse. Before this project, the anaesthetic to PACU nursing handover routinely consisted of theatre number and patient name; after this project, the handover now contains the patient's airway status which is a prompt to ensure the HME filter is left in place on transfer. Including this in the handover allows for the receiving PACU nurse to be appropriately allocated and Level 3 surgical mask to be donned prior to the patient's arrival. The Level 3 surgical mask remains in use until the high aerosol risk procedure is completed.

This project also included the introduction of an anaesthetic to PACU handover 'cheat sheet' which was placed near the phone in every theatre. The sheet summarises key points for a succinct ISBAR structured handover, including operating room number, patient name, operation performed, anaesthetic given, airway status / HME filter present, and any intra-operative issues and/or patient alerts. Lanyard-sized 'cheat sheet' cards were also made for anaesthetic nurses.

\section{Recommendations}

These relatively minor changes to routine PPE and handover within the perioperative department are recommended to help protect both patients and staff from acquiring and spreading infectious airway diseases, such as COVID-19. 


\section{References}

1. Australian Society of Anaesthetists (ASA). Anaesthesia and caring for patients during the COVID-19 outbreak [Internet]. Sydney: ASA; 2020 [cited 2020 October 24]. Available from: https: / /asapublicaccess.s3.apsoutheast-2.amazonaws.com/website/ ASA_airway_management.pdf.

2. World Health Organization (WHO). Coronavirus disease (COVID-19) Situation report - 46 [Internet]. Geneva: WHO; 2020 [cited 2020 November 16]. Available from: https://www.who.int/docs/default-source/ coronaviruse/situation-reports/20200306.

3. Department of Health. Physical distancing for coronavirus (COVID-19) [Internet]. Canberra: Australian Government; 2020 [updated 2020 September 23; cited 2020 November 15]. Available from: www.health.gov.au/news/health-alerts/ novel-coronavirus-2019-ncov-health-alert how-to-protect-yourself-and-others-fromcoronavirus-covid-19/physical-distancingfor-coronavirus-covid-19.
4. United States Environmental Protection Agency (EPA). Air cleaners, HVAC filters, and coronavirus (COVID-19) [Internet]. Washington: EPA; 2020 [cited 2021 January 13]. Available from: www.epa.gov/ coronavirus/air-cleaners-hvac-filters-andcoronavirus-covid-19.

5. Gupta N, Sachdev A, Bansal A, Sood A, Sharan T, Patki V. Personal protective equipment during COVID-19 epidemic. J Pediatr Crit Care 2020;7(7):22-30. DOI: 10.4103/JPCC.JPCC_75_20.

6. Koo C, Lee SY, Chung SH, Ryu J. Deep vs. awake extubation and LMA removal in terms of airway complications in pediatric patients undergoing anesthesia: a systemic review and meta-analysis. J Clin Med 2018;7(10):353. DOI: $10.3390 /$ jcm7100353
7. Zucco L, Levy N, Ketchandji D, Aziz M, Ramachandran SK. An update on the perioperative considerations for COVID-19 severe acute respiratory syndrome coronavirus-2 (SARS-CoV-2). APSF Newsletter 2020;35(2). Available from: www.apsf.org/ article/an-update-on-the-perioperativeconsiderations-for-covid-19-severe-acuterespiratory-syndrome-coronavirus-2-sarscov-2.

8. Department of Health. Guidance on use of personal protective equipment (PPE) in hospitals during the covid-19 outbreak [Internet]. Canberra: Australian Government; 2020 [updated 2020 November 12; cited 2020 November 16]. Available from: www.health.gov.au/resources/publications/ guidance-on-the-use-of-personalprotective-equipment-ppe-in-hospitalsduring-the-covid-19-outbreak. 